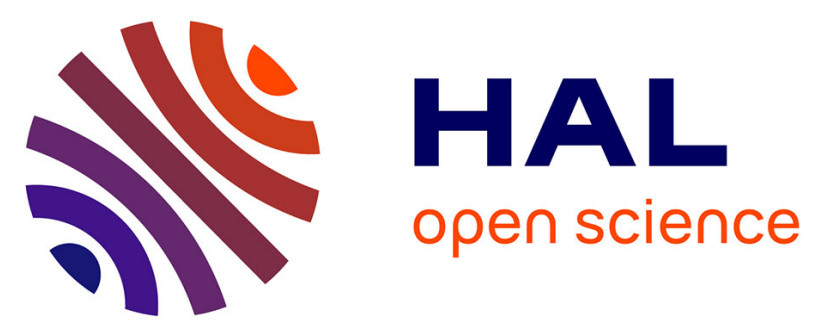

\title{
Delayed Gamma Measurements in Different Nuclear Research Reactors Bringing Out the Importance of Their Contribution in Gamma Flux Calculations
}

D. Fourmentel, V. Radulovic, L. Barbot, J-F. Villard, G. Zerovnik, L. Snoj, M. Tarchalski, K. Pytel, F. Malouch

\section{To cite this version:}

D. Fourmentel, V. Radulovic, L. Barbot, J-F. Villard, G. Zerovnik, et al.. Delayed Gamma Measurements in Different Nuclear Research Reactors Bringing Out the Importance of Their Contribution in Gamma Flux Calculations. IEEE Transactions on Nuclear Science, 2016, 63 (6), pp.2875-2879. 10.1109/tns.2016.2608985 . cea-02384470

\section{HAL Id: cea-02384470 https: / hal-cea.archives-ouvertes.fr/cea-02384470}

Submitted on 28 Nov 2019

HAL is a multi-disciplinary open access archive for the deposit and dissemination of scientific research documents, whether they are published or not. The documents may come from teaching and research institutions in France or abroad, or from public or private research centers.
L'archive ouverte pluridisciplinaire HAL, est destinée au dépôt et à la diffusion de documents scientifiques de niveau recherche, publiés ou non, émanant des établissements d'enseignement et de recherche français ou étrangers, des laboratoires publics ou privés. 


\title{
Delayed Gamma Measurements in Different Nuclear Research Reactors Bringing Out the Importance of the Delayed Contribution in Gamma Flux Calculations
}

\author{
D. Fourmentel, V. Radulović, L. Barbot, J-F. Villard, G. Žerovnik, L. Snoj, M. Tarchalski, K. Pytel, F. Malouch
}

\begin{abstract}
Neutron and gamma flux levels are key parameters in nuclear research reactors. In Material Testing Reactors, such as the future Jules Horowitz Reactor, under construction at the French Alternative Energies and Atomic Energy Commission (CEA Cadarache, France), the expected gamma flux levels are very high (nuclear heating is of the order of $20 \mathrm{~W} / \mathrm{g}$ at $100 \mathrm{MWth}$ ). As gamma rays deposit their energy in the reactor structures and structural materials it is important to take them into account when designing irradiation devices. There are only a few sensors which allow measurements of the nuclear heating [12]; a recent development at the CEA Cadarache allows measurements of the gamma flux using a miniature ionization chamber (MIC) [3]. The measured MIC response is often compared with calculation using modern Monte Carlo (MC) neutron and photon transport codes, such as TRIPOLI-4 and MCNP6. In these calculations only the production of prompt gamma rays in the reactor is usually modelled thus neglecting the delayed gamma rays. Hence calculations and measurements are usually in better accordance for the neutron flux than for the gamma flux. In this paper we study the contribution of delayed gamma rays to the total MIC signal in order to estimate the systematic error in gamma flux MC calculations.

In order to experimentally determine the delayed gamma flux contributions to the MIC response, we performed gamma flux measurements with CEA developed MIC at three different research reactors: the OSIRIS reactor (MTR - 70 MWth at CEA Saclay, France), the TRIGA MARK II reactor (TRIGA - 250 kWth at the Jožef Stefan Institute, Slovenia) and the MARIA reactor (MTR - 30 MWth at the National Center for Nuclear Research, Poland). In order to experimentally assess the delayed gamma flux contribution to the total gamma flux, several reactor shut down (scram) experiments were performed specifically for the purpose of the measurements. Results show that on average about $30 \%$ of the MIC signal is due to the delayed gamma rays. In this paper we describe experiments in each of the three reactors and how we estimate delayed gamma rays with MIC measurements. The results and perspectives are discussed.
\end{abstract}

D. Fourmentel, V. Radulović, L. Barbot and J-F. Villard are with the Alternative Energies and Atomic Energy Commission: CEA, DEN, DER, Instrumentation Sensors and Dosimetry Laboratory, Cadarache, 13108 SaintPaul-Lez-Durance, France (e-mail: damien.fourmentel@cea.fr).

G. Žerovnik and L. Snoj are with the Reactor Physics Department, Jožef Stefan Institute, SI-1000 Ljubljana, Slovenia.

M. Tarchalski and K. Pytel are with the National Centre for Nuclear Research A.Soltana 7, 05-400 Swierk, Poland.

F. Malouch is with the Alternative Energies and Atomic Energy Commission: CEA, DEN, DM2S, Saclay, 91191, Gif-sur-Yvette, France.

\section{INTRODUCTION}

Neutron and gamma flux levels are key parameters in nuclear research reactors. In Material Testing Reactors, such as the future Jules Horowitz Reactor, under construction at the French Alternative Energies and Atomic Energy Commission (CEA Cadarache, France), the expected gamma flux levels are very high (nuclear heating is of the order of $20 \mathrm{~W} / \mathrm{g}$ at 100 MWth). As gamma rays deposit their energy in the reactor structures and structural materials it is important to take them into account when designing devices for experimental channels.

Significant efforts have been made these last years by CEA, and particularly by the Instrumentation, Sensors and Dosimetry Laboratory, in order to improve the capability to perform accurate in-pile measurements for a better evaluation of the irradiation conditions in research reactors.

There are only a few sensors which allow measurements of the nuclear heating [1-2]. In this context a recent development at the CEA Cadarache allows measurements of the gamma flux using a miniature ionization chamber (MIC) $[3,6]$. The measured MIC response is often compared with calculation using modern Monte Carlo (MC) neutron and photon transport codes, such as TRIPOLI-4 [7] and MCNP6 [8]. In these calculations only the production of prompt gamma rays in the reactor is usually modelled thus neglecting the delayed gamma rays. Hence calculations and measurements are usually in better accordance for the neutron flux than for the gamma flux. In this paper we study the contribution of delayed gamma rays to the total MIC signal in order to estimate the systematic error in MC calculations. In order to experimentally determine the delayed gamma flux contributions to the MIC response, we performed gamma flux measurements with CEA developed MIC at three different research reactors: the OSIRIS reactor (MTR - 70 MWth at CEA Saclay, France), the TRIGA MARK II reactor (TRIGA - $250 \mathrm{kWth}$ at the Jožef Stefan Institute, Slovenia) and the MARIA reactor (MTR - 30 MWth at the National Center for Nuclear Research, Poland). In order to experimentally assess the delayed gamma flux contribution to the total gamma flux, several reactor shut down (scram) experiments were performed specifically for the purpose of the measurements. 
In this paper we describe the experiment for each of the three reactors. In particular for the OSIRIS reactor, prompt and delayed gamma fluxes have been calculated and compared with measurements. These results are discussed.

\section{OSIRIS REACTOR EXPERIMENT}

OSIRIS reactor is a Material Testing Reactor at the French Alternative Energies and Atomic Energy Commission (CEA Saclay, France) with a nominal power of $70 \mathrm{MWth}$. It is operated with low enriched fuel (19.75 wt. \% uranium 235) and is light-water moderated. An experiment called VASCO was led in 2014 to improve neutron and photon flux measurements with different types of sensors [4]. In particular in this experiment a MIC was used to measure on-line the gamma flux compared with delayed and prompt gamma spectra calculations performed with TRIPOLI4 code [7]. Indeed, for this experiment, specific delayed gamma calculations were performed with TRIPOLI4 [4].

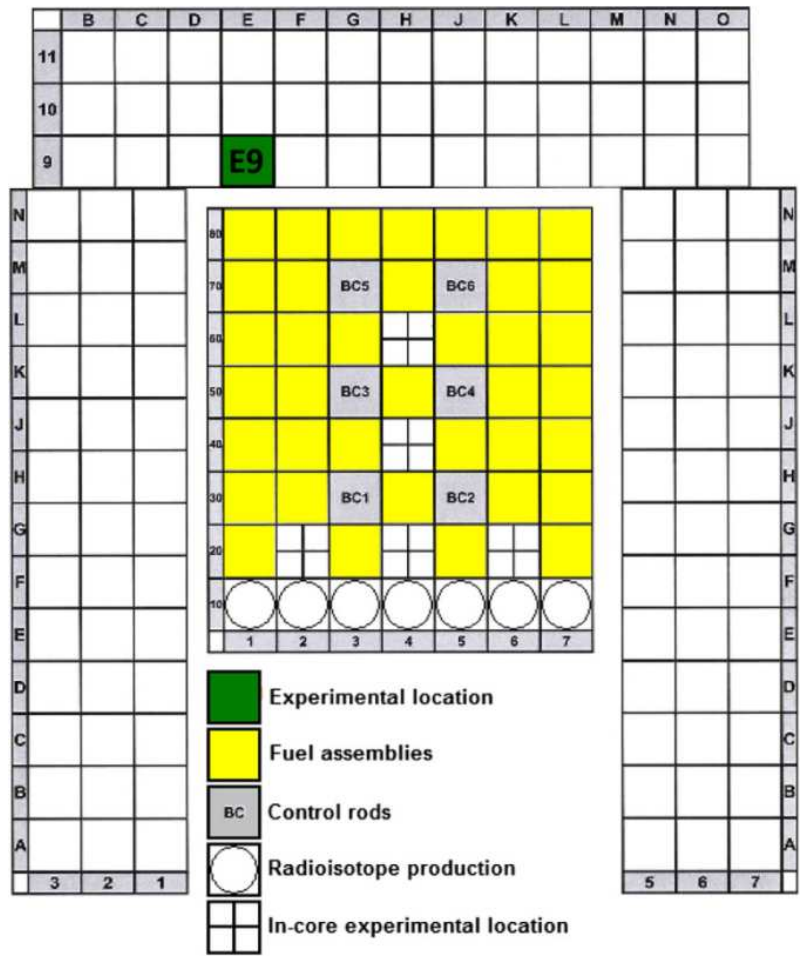

Fig.1: overview of one VASCO experimental location in OSIRIS reactor.

\section{A. Measurements with MIC}

To evaluate the delayed gamma level in the experimental location we measured the signal of the MIC during a scram at the end of the running cycle. For the scram experiment the measurements were performed with a sampling time of $100 \mathrm{~ms}$ using an electrometer (cf. Fig.2).

Before the scram we measured during $1 \mathrm{~min}$ an average signal of $2.35 .10^{-6} \mathrm{~A} \pm 0.8 \%$. Table 1 details MIC signal versus time and during the control rods shut down. Delayed gamma column is calculated by the ratio of each measurement with the average current measured just before the scram. The last column is the difference between two successive delayed gamma calculations. Table 1 shows an approximate delayed gamma level of about $30 \%$. Indeed roughly $400 \mathrm{~ms}$ after the scram we notice a relative delayed gamma of $30.8 \%$ and a deviation of $0.1 \%$ with the last measurement. It means from this point the control rods are down and the signal is only due to delayed gamma from fuels fission products and activation decay of the core structure.

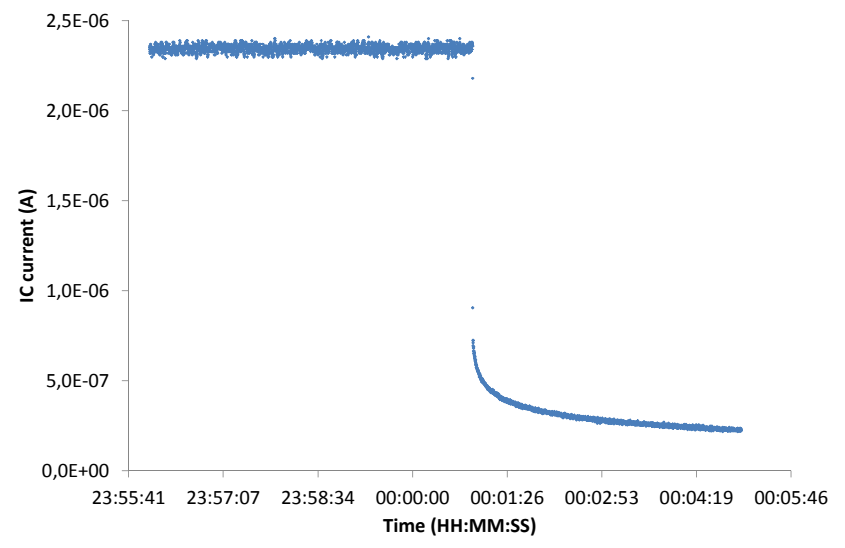

Fig.2: MIC measurements during the scram in OSIRIS reactor

TABLE 1: MIC MEASUREMENTS DURING THE SCRAM IN OSIRIS REACTOR

\begin{tabular}{cccc} 
Time & IC (A) & Delayed $\gamma(\%)$ & Delta (\%) \\
\hline $00: 54,9$ & $2,36 \mathrm{E}-06$ & & \\
$00: 55,0$ & $2,18 \mathrm{E}-06$ & $92,9 \%$ & \\
$00: 55,1$ & $9,05 \mathrm{E}-07$ & $38,6 \%$ & $-54,3 \%$ \\
$00: 55,2$ & $7,25 \mathrm{E}-07$ & $30,9 \%$ & $-7,7 \%$ \\
$00: 55,3$ & $7,22 \mathrm{E}-07$ & $30,8 \%$ & $-0,1 \%$ \\
$00: 55,4$ & $7,11 \mathrm{E}-07$ & $30,3 \%$ & $-0,5 \%$ \\
$00: 55,5$ & $6,94 \mathrm{E}-07$ & $29,6 \%$ & $-0,7 \%$ \\
$00: 55,6$ & $6,89 \mathrm{E}-07$ & $29,4 \%$ & $-0,2 \%$ \\
$00: 55,7$ & $6,85 \mathrm{E}-07$ & $29,2 \%$ & $-0,2 \%$ \\
$00: 55,8$ & $6,81 \mathrm{E}-07$ & $29,0 \%$ & $-0,2 \%$ \\
$00: 55,9$ & $6,65 \mathrm{E}-07$ & $28,3 \%$ & $-0,7 \%$ \\
\hline
\end{tabular}

\section{B. Prompt and Delayed Gamma Spectra Calculations}

For VASCO experiment, prompt and delayed gamma spectra calculations (cf. Fig.3) were performed with TRIPOLI code.

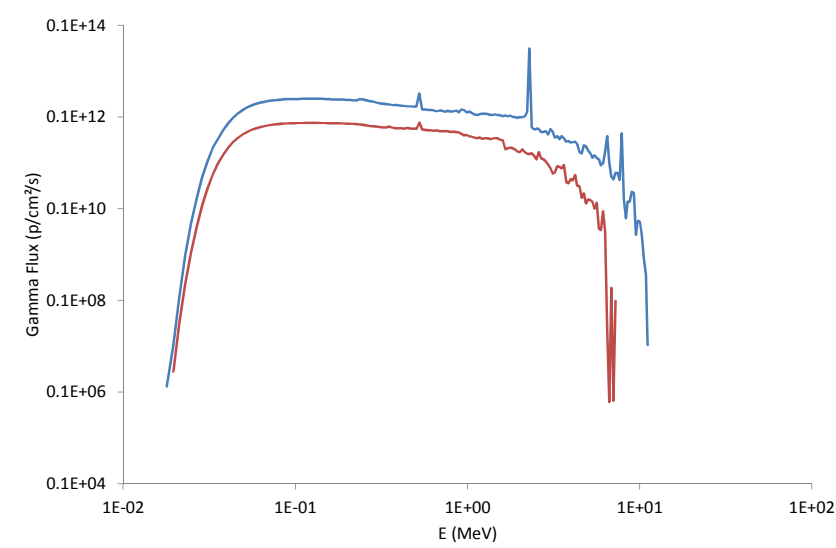

Fig.3: prompt gamma (blue) and delayed gamma (red) flux calculations for VASCO experiment. 
Delayed gamma flux contributes for $19.9 \%$ to the total gamma flux calculations. We estimate experimentally a delayed gamma flux about $30 \%$. Thus a discrepancy of about $10 \%$ is observed between MIC measurements and calculation. The origins of this discrepancy can be diverse. Even if delayed gamma flux is calculated, calculations do not take into account the decay activation of the structures. Furthermore the uncertainties of MIC measurements and TRIPOLI calculations (not only statistics results) are still under evaluation. At last, a discrepancy of $10 \%$ is really encouraging for the MIC to demonstrate its ability to monitor the gamma flux.

\section{MARIA REACTOR EXPERIMENT}

MARIA reactor is a Material Testing Reactor at the National Centre for Nuclear Research (NCBJ, Poland) with a nominal power of $30 \mathrm{MWth}$. It is now operated with low enriched fuel (19.75\% uranium 235) and is moderated by light water and beryllium. An experiment called GAMMA MAJOR was led in 2014 to perform neutron flux and nuclear heating measurements with different types of sensors [5]. Like in OSIRIS reactor, a similar MIC was used to measure on-line the gamma flux and to evaluate experimentally the delayed gamma and the total gamma fluxes.

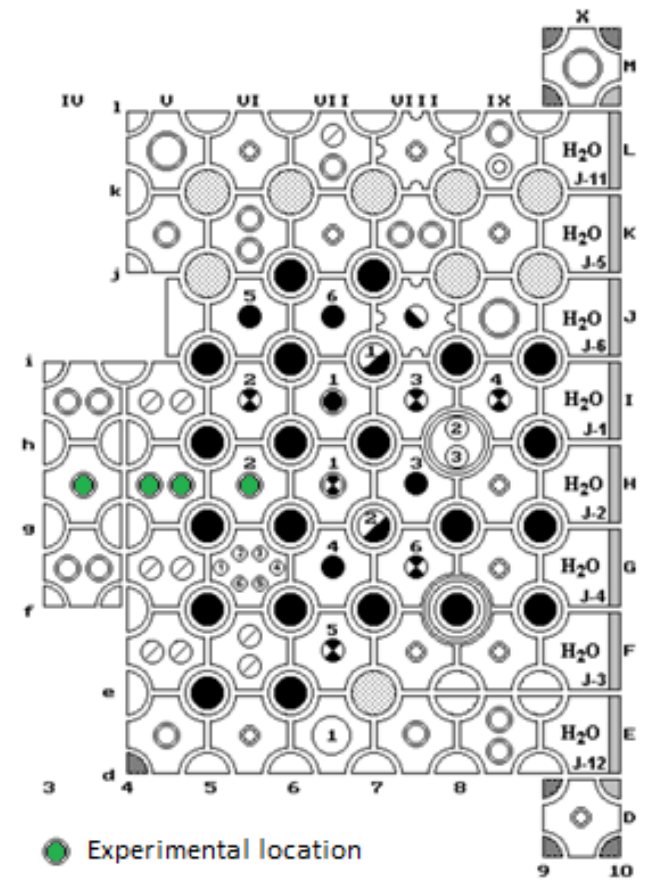

Fig.4: overview of MARIA reactor with the four experimental locations

During the GAMMA MAJOR experiment, nominal running power was $15 \mathrm{MWth}$ and several scrams were performed. Moreover before scram tests the experimental device was withdrawn quickly to estimate the gamma flux due to the activation of the device itself. The MIC measurements were performed with a sampling time of $500 \mathrm{~ms}$ using an electrometer.

Before the scram in $\mathrm{H}-\mathrm{VB}$ location we measured during $1 \mathrm{~min}$ an average signal of $3.23 .10^{-5} \mathrm{~A} \pm 0.1 \%$. Table 2 is structured as Table 1 (cf. II.A) and shows an approximate delayed gamma of about $30 \%$. Due to the large sampling time it is difficult to estimate the relative delayed gamma as precisely as in OSIRIS experiment (cf. II.A). However we can estimate delayed gamma flux in the core about $37 \%$. This estimation is bigger than delayed gamma estimation of OSIRIS reactor. Indeed in MARIA reactor MIC was in the core while in OSRIS reactor MIC was in reflector. Delayed gammas from activation decay of the structures are bigger in the core of MARIA reactor.

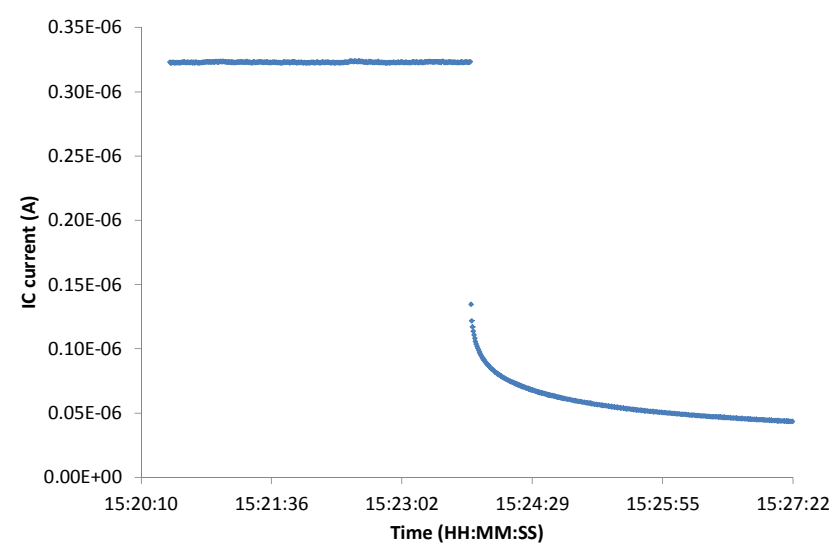

Fig.5: MIC measurements in H-VB location during a scram

TABLE 2: MIC MEASUREMENTS DURING A SCRAM AT MARIA REACTOR

\begin{tabular}{cccc} 
Time & IC (A) & Delayed $\gamma(\%)$ & Ddelta (\%) \\
\hline $23: 47,7$ & $3,23 \mathrm{E}-05$ & & \\
$23: 48,2$ & $1,35 \mathrm{E}-05$ & $41,7 \%$ & \\
$23: 48,7$ & $1,22 \mathrm{E}-05$ & $37,7 \%$ & $-4,0 \%$ \\
$23: 49,2$ & $1,17 \mathrm{E}-05$ & $36,3 \%$ & $-1,4 \%$ \\
$23: 49,7$ & $1,14 \mathrm{E}-05$ & $35,2 \%$ & $-1,1 \%$ \\
$23: 50,2$ & $1,11 \mathrm{E}-05$ & $34,3 \%$ & $-0,9 \%$ \\
$23: 50,7$ & $1,08 \mathrm{E}-05$ & $33,5 \%$ & $-0,8 \%$ \\
$23: 51,2$ & $1,06 \mathrm{E}-05$ & $32,8 \%$ & $-0,7 \%$ \\
$23: 51,7$ & $1,04 \mathrm{E}-05$ & $32,2 \%$ & $-0,6 \%$ \\
$23: 52,2$ & $1,02 \mathrm{E}-05$ & $31,6 \%$ & $-0,6 \%$ \\
$23: 52,7$ & $1,01 \mathrm{E}-05$ & $31,1 \%$ & $-0,5 \%$ \\
$23: 53,2$ & $9,91 \mathrm{E}-06$ & $30,7 \%$ & $-0,4 \%$ \\
\hline
\end{tabular}

In addition, in this experiment we wanted to estimate MIC signal due to the activation decay of the device itself. For this experiment we withdrew manually the device quickly during the reactor running and we measured the MIC signal evolution (cf. Fig.6 and Table 3).

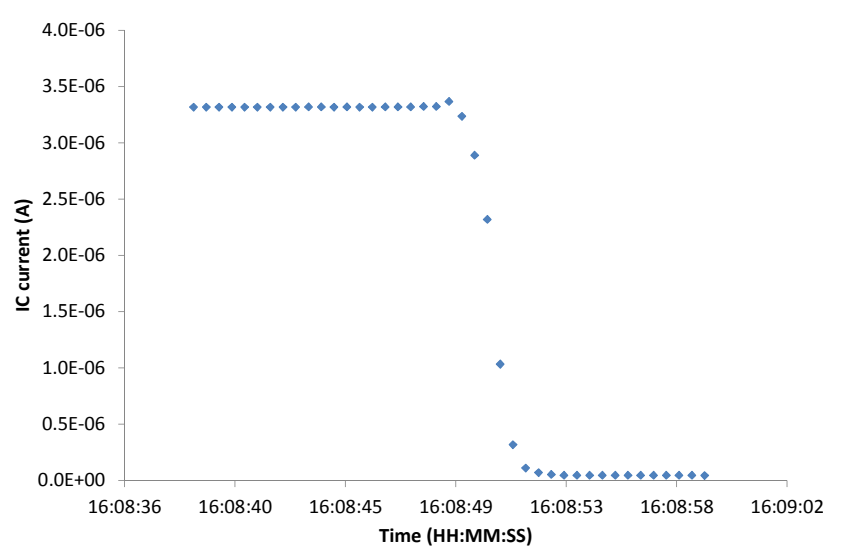

Fig.6: MIC measurements in H-VB location during the device withdrawal 
Table 3 shows a low gamma contribution due to the device of about $1.4 \%$. This experiment allows evaluating the background signal of MIC for the absolute gamma flux evaluations.

TABLE 3: MIC MEASUREMENTS DURING THE DEVICE WITHDRAWAL

\begin{tabular}{cccc} 
Time & IC (A) & Delayed $\gamma(\%)$ & Ddelta (\%) \\
\hline $08: 48,8$ & $3,37 \mathrm{E}-05$ & & \\
$08: 49,3$ & $3,24 \mathrm{E}-05$ & $97,5 \%$ & \\
$08: 49,8$ & $2,89 \mathrm{E}-05$ & $87,1 \%$ & $-10,4 \%$ \\
$08: 50,3$ & $2,32 \mathrm{E}-05$ & $69,9 \%$ & $-17,2 \%$ \\
$08: 50,8$ & $1,03 \mathrm{E}-05$ & $31,1 \%$ & $-38,8 \%$ \\
$08: 51,3$ & $3,18 \mathrm{E}-06$ & $9,6 \%$ & $-21,6 \%$ \\
$08: 51,8$ & $1,10 \mathrm{E}-06$ & $3,3 \%$ & $-6,3 \%$ \\
$08: 52,3$ & $6,92 \mathrm{E}-07$ & $2,1 \%$ & $-1,2 \%$ \\
$08: 52,8$ & $5,21 \mathrm{E}-07$ & $1,6 \%$ & $-0,5 \%$ \\
$08: 53,3$ & $4,69 \mathrm{E}-07$ & $1,4 \%$ & $-0,2 \%$ \\
$08: 53,8$ & $4,55 \mathrm{E}-07$ & $1,4 \%$ & $0,0 \%$ \\
\hline
\end{tabular}

These MIC measurements demonstrate that in the conditions of the MARIA experiment $37 \%$ of the gamma flux comes from delayed gamma.

\section{TRIGA MARK II REACTOR EXPERIMENT}

The TRIGA MARK II reactor at the Josef Stefan Institute (JSI, Slovenia) is a pool-type light water reactor with a nominal power of $250 \mathrm{kWth}$. It is operated with low enriched fuel $(20 \%)$. This reactor core is surrounded by an annular graphite reflector and is cooled by natural convection. An experiment was led in 2014 to improve gamma flux measurements with a MIC [6] similar to the one used for OSIRIS and MARIA reactor experiments. Several scrams were performed to evaluate experimentally the delayed gamma flux (cf. Fig.7).

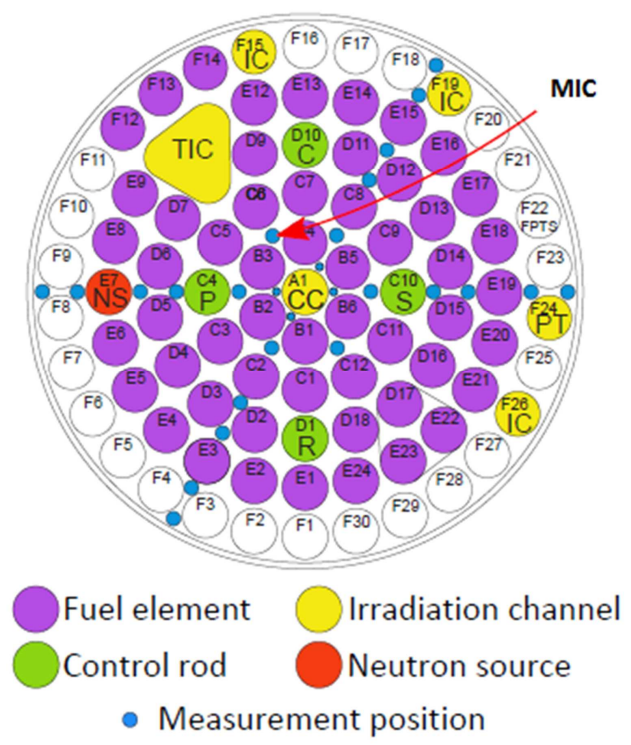

Fig.7: overview of TRIGA MARK II reactor with the experimental location.

MIC measurements were performed with a sampling time of $100 \mathrm{~ms}$ during scram tests. Before the scram described in this paper we measured during $1 \mathrm{~min}$ an average signal of 1.25.10 ${ }^{-6} \mathrm{~A} \pm 0.6 \%$.

Table 4 shows an approximate delayed gamma of about $30 \%$. We notice $400 \mathrm{~ms}$ after the scram a relative delayed gamma of $30.7 \%$ and a deviation of $1.0 \%$ with the last measurement. It means from this point the control rods are down and the signal is due to delayed gamma from the fuels and activation decay of the structure of the core.

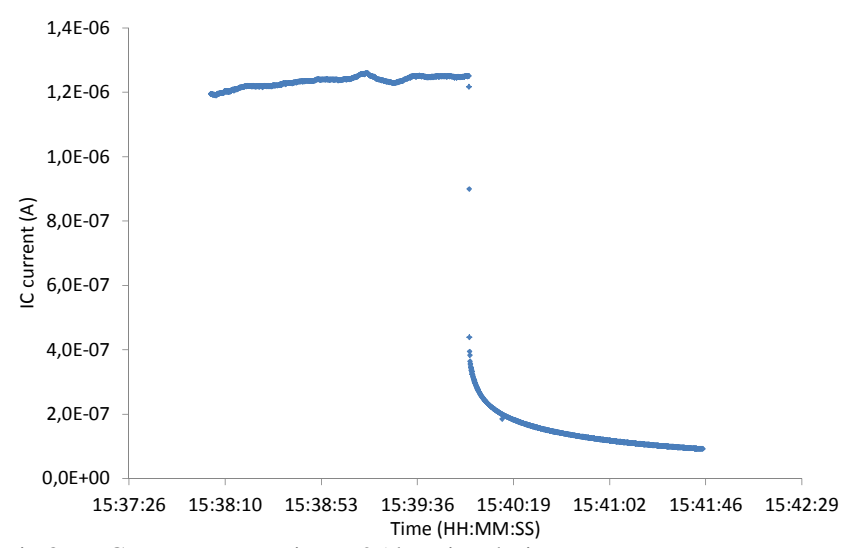

Fig.8: MIC measurements in MP25 location during a scram

TABLE 4: MIC MEASUREMENTS DURING A SCRAM AT TRIGA MARKII

\begin{tabular}{cccc} 
Time & IC (A) & Delayed $\gamma(\%)$ & Ddelta (\%) \\
\hline $39: 59,1$ & $1,25 E-06$ & & \\
$39: 59,2$ & $1,22 E-06$ & $97,7 \%$ & \\
$39: 59,3$ & $8,99 E-07$ & $72,2 \%$ & $-25,5 \%$ \\
$39: 59,4$ & $4,39 E-07$ & $35,3 \%$ & $-37,0 \%$ \\
$39: 59,5$ & $3,95 E-07$ & $31,7 \%$ & $-3,6 \%$ \\
$39: 59,6$ & $3,83 E-07$ & $30,7 \%$ & $-1,0 \%$ \\
$39: 59,7$ & $3,64 \mathrm{E}-07$ & $29,2 \%$ & $-1,5 \%$ \\
$39: 59,8$ & $3,57 \mathrm{E}-07$ & $28,7 \%$ & $-0,5 \%$ \\
$39: 59,9$ & $3,54 \mathrm{E}-07$ & $28,4 \%$ & $-0,3 \%$ \\
$40: 00,0$ & $3,47 \mathrm{E}-07$ & $27,9 \%$ & $-0,5 \%$ \\
$40: 00,1$ & $3,44 \mathrm{E}-07$ & $27,6 \%$ & $-0,2 \%$ \\
\hline
\end{tabular}

For this scram experiment prompt gamma spectrum was calculated by using the MCNP code. These MIC measurements demonstrate that in the conditions of the TRIGA experiment $30 \%$ of the gamma flux comes from delayed gamma.

\section{CONCLUSION}

We determine experimentally delayed gamma flux contributions with a MIC sensor in three different research reactors by scram experiments. Results have shown that the delayed gamma flux contribution to the total gamma flux is an average about $30 \%$. Moreover, OSIRIS experiment allowed comparing these results with delayed gamma flux calculations with TRIPOLI4 code.

MIC sensor appears to be reliable to monitor the gamma flux and to validate Monte Carlo gamma calculations. With these promising results, we will now focus on the improvement of the MIC signal analyzing for a better evaluation of the absolute gamma level. We also intend to study and test the ageing of this type of sensor for future applications in material testing reactors. 


\section{REFERENCES}

[1] H. Carcreff, et al., "Development, Calibration, and Experimental Results Obtained With an Innovative Calorimeter (CALMOS) for Nuclear Heating Measurements", IEEE Transactions on Nuclear Science, Vol: 59, Issue: 4 Part: 2, pp 1369-1376, 2012.

[2] D. Fourmentel, et al., "Nuclear Heating Measurements in Material Testing Reactor: a Comparison Between a Differential Calorimeter And a Gamma Thermometer", IEEE Transactions on Nuclear Science, Vol. 60, Issue: 1, pp. 328-335, 2013.

[3] D. Fourmentel, et al., "Measurement of photon flux with a miniature gas ionization chamber in a MTR", Nuclear Instruments and Methods in Physics Research Section A, Vol 724, pp. 76-82, 2013.

[4] L. Barbot, et al., "Calculation to experiment comparison of SPND signals in various nuclear reactor environments", ANIMMA2015.

[5] M. Tarchalski, et al., "Development and experimental qualification of a calculation scheme for the evaluation of gamma heating in experimental reactors. Application to MARIA and Jules Horowitz (JHR) MTR Reactors", ANIMMA2015.

[6] V. Radulovic, et al., "Measurements of miniature ionization chamber currents in the JSI TRIGA Mark II reactor demonstrate the importance of the delayed contribution to the photon field in nuclear reactors", paper submitted in 2015 to Nuclear Instruments and Methods in Physics Research Section A.

[7] TRIPOLI-4 Monte Carlo Transport Code, http:www.nea.fr.abs/html/nea1716.html (2013).

[8] [1]X-5 Monte Carlo Team, MCNP6 User's Manual, Version 1.0, May 2013, LA-CP-13-00634. 